\title{
10 Convergence and divergence of workers' environment, associations, and access to social protection
}

\author{
Sectoral and country \\ comparisons
}

\author{
Winnie Mitullah, Lone Riisgaard, \\ Nina Torm, Aloyce Gervas, Raphael Indimuli, \\ Anne W. Kamau and Godbertha Kinyondo
}

\section{Introduction}

The literature on the informal economy tends to make generalizations across sectors and countries. While this is true to some extent, the comparison between Kenya and Tanzania reveals both convergence and divergence depending on the issue of investigation. The two countries have different historical development trajectories, which are also reflected in the development of the different industrial sectors and in associational life. On the other hand, Kenya embraced the spirit of harambee (pulling together) right at independence, an approach which enabled many workers and families to cushion themselves in a capitalist liberal economy which was less concerned about those who could not fend for themselves. On the other hand, Tanzania had the Ujamaa modelled on an African collective approach but steered by the state that ensured that basic services were available to citizens, albeit in a limited manner.

These differences have had an effect on growth and development of the two countries, including the development of the informal sector. The capitalist state in Kenya nurtured a society of gross inequalities with a large informal sector, while the Tanzanian state had comparatively fewer inequalities and a comparatively smaller informal sector. Consequently, Kenya has had a longer experience handling informality, dating back to the famous 1972 ILO report (ILO, 1972) focusing on employment, incomes, and inequalities in Kenya. This long experience is demonstrated by transport SACCOs which are operating as quasi-legal entities working closely with the government in governance of the sector, while in the Tanzanian transport sector, cooperation is informal. The trade sector in Kenya is following a similar pattern to the transport sector with representation of informal traders in the Micro and Small Enterprises Authority (MSEA). Tanzania does not have such formal institutional linkages between informal workers 
and the government, although intermittent support for the informal sector and ad-hoc coordination and consultation does exist.

One aspect which cuts across the three sectors covered in this study and across countries is the work environment. Informal workers operate under difficult and precarious working conditions often without contracts, social protection, and labour rights. Of particular concern is the lack of contracts among workers who work in an identifiable employment relationship, in particular, the transport and construction workers. This undermines their chances of accessing labour rights as provided in both Kenya's and Tanzania's policies and regulations. Although the majority, especially the micro-traders, operate as own-account workers, even in cases where workers are employed by firms such as in the construction sector, the multi-layered nature of employment subjects workers to sub-contracting without individual contracts and security. The situation is not different in the transport sectors. In Kenya, the formation of transport SACCOs and franchises has not resolved the issue of contracts, and - where they have contracts - they are not enforced, resulting in an inability to claim and access labour rights (Table 10.1).

Another aspect which cuts across is a rich associational life, where workers' collective associations provide a range of services to their members, many of which can be considered informal social protection measures. As seen throughout this volume, the services provided by associations differ markedly across sectors (and by country), which testifies to the importance of sector-specific insights. Yet, common across sectors in both countries is that entry into associations requires payment of fees and adherence to group constitutions or regulations.

In order to compare and analyze sectors across countries, four major issues are discussed in this chapter: (i) How key worker characteristics relate to workers' access to formal and informal insurance by country and sector, (ii) How governance frameworks across countries and sectors function, including associational differences and power resources available to associations, (iii) Whether unions facilitate representation of informal workers, and (iv) How associations provide preventive, promotive, and transformative social protection measures to their members in line with the framework developed by Devereux and SabatesWheeler (2004). Each of the corresponding sub-sections teases out convergences across the sectors in Kenya and Tanzania, whilst bringing out unique aspects pertaining to each sector in each country. Last, the conclusion pulls out the key findings, noting the difference and similarities between the countries and the sectors.

Table 10.1 Formal social insurance coverage (percent)

\begin{tabular}{lllll}
\hline & Construction & Trade & Transport & Overall \\
\hline Kenya & 35 & 39 & 50 & 41 \\
Tanzania & 17 & 22 & 16 & 19 \\
\hline
\end{tabular}

Source: Author's elaboration. 


\section{Who are the informal workers?}

On a global scale, the rate of informality is higher among men than among women; yet, in low- and lower-middle-income countries, women are more likely than men to be in informal employment (ILO, 2019). For instance, in Africa, 90 percent of employed women are in informal employment in contrast to 83 percent of men (ibid.). In the project on which this volume is based, a higher share of women informal workers is found among the micro-traders in both Kenya and Tanzania, whereas the construction and transport sectors are dominated by young male workers. In the Kenyan construction industry, however, the male-female ratio seems to be changing slowly, as women are increasingly taking on special skills such as painting, electrical works, and masonry. Likewise, in transport, women are also gradually entering the sector, working mainly as conductors, yet almost absent among the motorcyclists.

Across the three sectors, we find that several worker characteristics differ along the gender dimension, although with some variation between Kenya and Tanzania. For instance, in Tanzania, women are more likely to contribute to formal social insurance, whilst in Kenya, they are less likely, and when it comes to association membership, this is more common among women in both countries. Women have a history of having barriers to formal credit facilities, and associations have always been their source of support and access to credit. In line with the general wage gap literature, male workers have higher average earnings, although the difference is more pronounced in Tanzania where women are more likely to possess assets. Across both countries, men are more highly educated and also more likely to attend training courses, whilst women are generally selftaught. Regarding worker types, in both countries, men dominate amongst wage-workers whilst women tend to be own-account, and in Tanzania, women are also more likely to be micro-firm owners. In Kenya, there is a variation in the transport sector where both men and women are wage-workers. Ownaccount operators are few, and when women join the sector, they work mainly as conductors while men occupy the better-paying jobs of drivers. These genderdivisions point to women having to combine reproductive work with their income-generating activities, and in the case of the transport sector in Kenya, it is also due to late entry of women in the sector, mainly considered to be men's work and a risky occupation. Interestingly, when looking at the challenges mentioned by informal workers, there are no major differences by gender; yet, Kenyan women workers mention working conditions and safety issues as more pressing, whilst Tanzanian women cite payment delays and few clients and/or competition as main concerns. For men, issues related to harassment/arrest/police cut across the countries, as do payment delays, and common to all workers across the countries are credit concerns. Finally, in terms of the benefits of association membership in both countries, women and men equally cite financial and social support as the most important which is in line with the credit challenge they face.

Apart from the gender dimension, workers in the informal economy differ widely along a number of other characteristics including education level, income, 
associational belonging, and social protection, and such differences are also reflected in our survey data. In terms of education, across the sectors, Tanzania has a much lower share of workers with completed secondary education (29 percent) compared with the share of workers that have primary education ( 62 percent). By contrast, in Kenya, the incidence of completed secondary education (and above) is at 47 percent, slightly higher than the share of workers with completed primary education (42 percent). As expected, our figures are lower than official secondary education enrolment figures for the entire population, which are 71 percent in Kenya (ROK, 2019a) and 32 percent in Tanzania (URT, 2019, p. 255). Finally, as also seen in Chapter 3 , participation in formal social insurance is much more likely for workers with secondary education and above, whilst education level is not a determinant of association membership.

Regarding income, we also find variation between the two countries and across sectors. As expected, given the general difference in wages and living standards between the two countries, median daily earnings are higher in Kenya compared with Tanzania among both traders and transport workers (see sectorspecific chapters for further detail). However, when it comes to construction, Tanzanian construction workers have median daily earnings that are almost on par with Kenyan workers, which, to a large extent, can be explained by the types of workers interviewed. For instance, in Tanzania, the construction workers included a higher share of masons, whilst, in Kenya, the majority sampled were helpers who are lower on the earnings hierarchy compared with masons who are the ones negotiating for jobs with sub-contractors, contractors, and clients and hiring helpers to assist. Relatedly, the informal worker earnings observed in Tanzania are comparable to those of formal sector workers, whilst, in Kenya, official monthly earnings are substantially above the informal earnings reported. When it comes to participation in formal social insurance, unlike education, this is not determined by earnings. However, in Kenya, association members have higher average earnings than non-members, whereas, in Tanzania, the opposite is the case (see Chapter 3 for more detail).

Finally, in terms of key informal worker challenges and benefits of associations, there are no major differences by income level, except that, in Tanzania, those mentioning the opportunity to save as a top benefit also have lower average earnings, which seem logical. In accordance with the general literature, we find that earnings increase with age (up until a certain point) as it is a measure of experience/seniority. Moreover, across sectors and all things being equal, worker age is correlated with an increased likelihood of listing health benefits (over voice and representation, work-related issues, and loans), whereas more educated workers list voice and representation over health as a main association benefit.

In terms of geography, construction workers in Tanzania have a higher percentage of workers operating in cities where they were born compared to Kenyan workers who were largely moving in search for jobs. This is partly explained by the higher (37 percent) level of urbanization in Tanzania (UN, 2019) compared to Kenya (28 percent) (ROK, 2019b). Furthermore, since most Tanzanian workers work in towns where they were born, they have higher chances of owning 


\section{Winnie Mitullah et al.}

property either by inheritance or buying land which is cheaper in Tanzania compared to Kenya. This difference is reflected in the data where 43 percent of Tanzanian workers own assets compared with 27 percent of Kenyans. Overall, association members have more assets than non-members, which could be either a reflection of more wealthy workers selecting to be in associations or the latter facilitating and/or providing financial support to their members.

In addition to the trends in gender, education, income, and worker-type characteristics, workers in the informal economy differ substantially in terms of their associational belonging, as seen throughout this volume, and discussed further in this chapter. However, on this dimension, one aspect that cuts across countries and sectors is the important role played by different workers' associations in filling the substantial formal social insurance gap by assisting members in accessing employment opportunities and cushioning members during difficult times such as sickness, death, and social welfare needs.

\section{Institutional and governance framework}

The deficits in contracting and social protection among informal workers prevail despite the varied sectoral institutional and governance frameworks that exist in each of the countries, albeit with marginal differences. Kenya is comparatively more advanced in putting in place institutions to govern the transport and trade sectors, while both countries are on par in respect to the construction sector. While having formal state institutions is expected to improve the general work environment, some of the institutions are largely not in harmony with the informal working environment and institutions of workers such as associations and networks which drive workers' operations on a daily basis. This is glaring in the area of social protection where many workers do not enrol in formal social insurance (SI) schemes due to complex bureaucratic procedures for accessing services and irregular incomes. Instead, they largely rely on associations for social protection due to the close reach and flexible non-bureaucratic processes. Thus, this section examines the formal governance institutions for the three sub-sectors across countries, and power resources and related applicability to formal workers.

\section{Formal institutions}

An examination of the three sectors reveals deficits in application of public policies, regulations, and standards. All informal workers can, privately or through registered associations, enrol voluntarily in the National Hospital Insurance Fund (NHIF) in both Kenya and Tanzania, and in Tanzania, the same arrangement is also available through the community health fund $(\mathrm{CHF})$ under the NHIF. The KIKOA scheme which previously provided for group registration of informal workers through their associations in Tanzania had potential as it attracted considerable interest from informal workers' associations, but it did not survive partly due to adverse selection problems. 
Although recent years have seen an expansion in informal membership rates in public schemes (see Chapter 2), overall, the latter seem not to work well for informal workers, as shown in the relatively low enrolment of workers participating in formal social insurance (health or pension). For the vast majority of workers in both countries, formal social insurance refers specifically to health insurance, and in both countries, individual NHIF enrolment also covers immediate family members. Thus, the measure of health insurance coverage provides a more accurate depiction of actual coverage, and according to our data, this is 41 percent for Kenya compared with 19 percent for Tanzania. These figures are in line with the official coverage rates which are around 39 percent for Kenya (KNBS, 2019) and 22 percent for Tanzania (Jacob \& Pedersen, 2018). The general picture of a much higher formal social insurance coverage among informal sector workers in Kenya is reflected at the sectoral level; yet, the difference is particularly stark in the transport sector, where 50 percent of Kenyan workers have health insurance coverage compared to only 16 percent in Tanzania, as seen in Table 10.1.

This difference in the transport sector is due to the specific set-up for informal transport workers in Kenya, whereby some bus companies/franchises or SACCOS commission certain savings to pay for the workers' NHIF (and NSSF) coverage. However, even in this case, membership remains largely voluntary. Additionally, for Kenya, the introduction of UHC in pilot counties - including Kisumu, one of the volume case studies - and intensified recruitment-drive by NHIF, could account for the higher Kenya figures. Further examination of the three sub-sectors shows convergence and divergence, as examined below.

In the construction sector, legislation such as Work Injury Benefit Act (WIBA), Occupational Safety and Health Act (OSHA), and Occupational Health and Safety (OHS) rules in Kenya and Workers Compensation Fund (WCF) in Tanzania are not being complied with. These institutions largely work for those formally employed, and yet, the majority of construction workers are operating informally. This has exposed the workers in both countries to exploitation by the industry, with formal enterprises employing workers on casual basis to avoid costs associated with employment. This leaves the workers with informal social protection schemes based on associations, relatives, friends, and good Samaritans as the only fall-back.

In the micro-trade sector, both countries, during the last few years, have seen less confrontations and conflicts between micro-traders and authorities, particularly in Kenya. The 2010 Kenya Constitution (ROK, 2010) takes a rights perspective, highlighting rights to social security, protection for marginalized groups, and participatory governance. One outcome of this has been the $\mathrm{Mi}$ cro and Small Enterprises (MSE) Act of 2012 which provides representation of micro-enterprises including micro-traders (see Chapter 7). In Tanzania, the change seems to be mainly due to the more positive attitude of the late president Pombe Magufuli (see Chapter 6). In comparison, the changes in Kenya are institutionalized in the legislation, whereas in Tanzania it is not and hence rather dependent on politics of the day and the approach of a particular politician at a given time. 
The transport sector, with its many actors and institutions, poses a challenge in respect to organization for social protection. The presence of a large informal workforce makes it difficult for the Tanzanian and Kenyan governments to regulate the sector, even though there are efforts - mainly in Kenya - to organize the sector through SACCOs and franchises. For instance, since 2010, it is a legal requirement for Kenyan matatu (PSV) workers to belong to a SACCO or a transport management company. The workers, however, remain informal and have daily remittance targets (Spooner \& Manga, 2019) that force them to work for long hours, to aggressively compete for passengers, and drive recklessly in order to increase the number of trips made per day, hence compromising on safety. In Tanzania, local authorities encourage the formation of associations in the transport sector for easier coordination, and rule-bound cooperation does exist, even if it is not institutionalized.

In sum, across sectors, the formal social insurance coverage gap in both countries is partly due to a lack of understanding of the importance of social insurance, coupled with meagre irregular earnings, the bureaucratic processes involved, and the structure of the schemes. In Kenya, this is also attributed to the government's failure to enforce regulations requiring transport workers to have social protection. Furthermore, formal social insurance schemes are mostly and historically designated to deal with the formal sector, thus lack capacity to deal with a more challenging but expanding informal sector. In the following sub-section, we discuss the power resources used by associations, and in the section thereafter, we provide examples of different types of informal social protection measures/services that associations offer their members.

\section{Associational power resources and the applicability to informal workers}

Informal workers and their associations in both countries wield associational, institutional, structural, and societal powers which they use to negotiate their work environment and livelihoods. As discussed in more detail in Chapter 1 of this edited volume, the PRA starts from the basic premise that, if organized, labour can successfully defend its interests by collectively mobilizing different power resources (Schmalz, Ludwig \& Webster, 2018). The approach was however developed to analyze the power resources available to trade unions - not informal workers. This begs the question of how useful the power resource approach is to cast light on informal worker associations. We argue that, if modified and employed with caution, the analytical typology still has explanatory power, particularly in highlighting how sector- and country-specific groups of informal workers have differing power resources available - specifically with regards to the transformative social protection measure of voice and representation - as discussed below. The applicability of the approach and the implications of applying it to informal workers will be discussed in more detail in the concluding chapter of this volume. 


\section{Associational power}

Associational power is derived from the formation of collective organizations of workers and, as mentioned, can lead to transformative social protection measures in the form of voice and representation. Given the context of informal workers, we included all the different types of collective associations created or engaged in by informal workers to advance their own interests and conditions. It is an open empirical question who might form relevant counterparts with regards to representation, as the case studies revealed instances of representation towards employers (in transport and construction), the police (transport and trade), as well as municipal and national level authorities (all sectors). Associational power understood in this broad manner is potentially of immense importance for informal workers. Other than numbers, the strength of associational power is associated with a number of factors such as effective organizational structure, member willingness to take action such as participating in campaigns, willingness to pay dues, and a strong collective identity. It is hard though to generalize about informal worker associations since, as illustrated throughout this book, they differ significantly in particular in the following parameters: resources, representational power, and key purpose of associations. Moreover, as seen in Table 10.2 , our survey data shows that the incidence of association membership varies substantially across the three sectors and between countries.

Overall, a higher percentage of informal workers are enrolled in associations in Kenya compared with Tanzania, and informal transport workers have a stronger associational life compared to informal traders and, in particular, compared to construction workers in both Kenya and in Tanzania. Hence, based on numbers, associational power differs substantially between sectors, and in general, Kenyan associations were often found to be more resourceful.

Nonetheless, there are more similarities in associations than differences when comparing the same sectors across countries. Workers' associations are structured to perform functions required by members, which are mainly assisting to find jobs and cushioning members during difficult times for construction workers in both countries; welfare and protecting trading sites for traders in both countries; government requirement for business, welfare, and negotiation for Kenya transport workers; and welfare and negotiation for transport workers in Tanzania. Interestingly, as the analysis in Chapter 3 shows, there is a significant correlation between informal association membership and access to formal

Table 10.2 Informal association membership shares (percent)

\begin{tabular}{lllll}
\hline & Construction & Trade & Transport & Overall \\
\hline Kenya & 33 & 47 & 57 & 48 \\
Tanzania & 19 & 34 & 50 & 34 \\
\hline
\end{tabular}

Source: Author's elaboration. 
social insurance, which holds across sectors and when other factors like earnings, education level, and location are taken into account. This relationship is stronger in Kenya where the share of association members that are enrolled in formal schemes is double at 40 percent compared with 21 percent in Tanzania; yet, further analysis reveals that the correlation between informal association membership and access to formal social insurance is mostly seen among transport workers in both Kenya and Tanzania.

In both the survey data and interviews, large sectoral differences were revealed with regards to representation and the key purpose of the associations. In terms of key benefits of associations, at a general level, the survey data reveal that, controlling for key worker characteristics, trade and transport workers list voice and loans as more important (compared with health benefits) relative to construction workers (i.e. the latter are relatively more likely to list health benefits as key association functions).

Most associations encountered in the construction sector were created to facilitate job-seeking while also providing cushioning for members and only a few worker associations were engaged in bargaining with employers. More specifically, a few associations in Kenya were found to represent members to raise voice and demand their rights, including demands for work-space, fighting harassment by local authorities, and demanding payment for workers' dues from subcontractors, contractors, and clients. In the survey, issues like wage delays and short contracts were listed as relatively more important challenges for construction workers, all things being equal. The construction sectors in the two countries differ slightly. In Tanzania, where members are actively participating in association meetings and contributing, associations are stronger. Old associations tend to be dormant while younger ones are more active. This can be partly explained by the fact that old associations may have achieved their intended goals. Furthermore, Tanzania associations do not have umbrella associations, while Kenya has umbrella associations, but very few workers belong to such associations. No informal construction workers were found to belong to unions, although there were earlier attempts in Tanzania to organize workers to join trade unions through the support of development partners, but this was not sustained. This is despite the existence of such associations, as evidenced in the study.

In transport, in general, workers are mainly organized around work-related challenges, particularly problems in dealing with authorities or employers while some associations are also created for the purposes of social welfare and protection. Correspondingly, the survey data shows that, for transport workers, key challenges include dealing with the police/authorities, client conflicts, and poor infrastructure. Transport associations in both countries present a fragmented patchwork often including break-away associations counting amongst them a range of transport unions. In Kenya, as mentioned earlier, legislative provisions have made the associational landscape quite particular for the matatu sub-sector.

A key directive of the legally mandated SACCOs and transport companies is to negotiate with authorities on issues affecting the sector. These include fleet operations, management, and responding to government directives. However, 
the issues addressed are mainly related to factors which might impede a smooth operation of the fleet and are not as such related to working conditions or rights to social protection. Hence, these associations mostly favour the interests of SACCOs and vehicle owners while paying little attention to the issues affecting workers. Therefore, they cannot really be considered vehicles for workers' associational power which would allow them to voice their concerns or to demand for better working conditions. Nonetheless, along with some of the well-functioning associations, some SACCOs and companies invest in workers' capacity-building by organizing training on a range of issues that include road safety, financial literacy, and investing in social protection among others.

It is in the micro-trade sector that we probably find the largest variety of associations varying from groups working in designated areas who organize access to work-space and market-level representation, over welfare groups, to larger and more robust umbrella structures organizing many different kinds of traders. With regards to associational power, what stood out from the research, particularly on traders, was whether the association belonged to a larger umbrella structure (e.g. VIBINDO in Tanzania and KENASVIT in Kenya). In general, associations linked to umbrella associations were able to offer different kinds of support to their affiliated groups, such as access to training and infrastructure to take up issues with regards to representation. By contrast, smaller stand-alone associations would often be more inward-looking. The larger and more robust umbrella associations were generally also the ones which would engage in voice and representation. In Tanzania, this included a trade union which is discussed in more detail in the last part of this chapter.

\section{Institutional power}

Institutional power is derived from laws, regulations, procedures, and practices that regulate the relationship between worker associations and employers as well as authorities. In the context of informal workers, sources of institutional power in our cases stem mainly from either specific provisions in the legal system or affiliation to trade unions, and we will discuss these in turn.

As already mentioned in the introduction to this chapter, Kenya has taken steps (albeit small) towards a more inclusive and participatory institutional set-up with the new constitution and particularly with the Micro and Small Enterprises (MSE) Act of 2012 which provides for representation of informal traders (represented via KENASVIT) amongst other groups. This means that, at least for the micro-trade sector, some form of representation is institutionalized.

In Tanzania, the change seems to have gone in the opposite direction with moves towards centralization and shrinking of civil society space more generally. As described in Chapter 7, a seat was given to a representative of an informal association on the National Employment Advisory Committee in 1999, but there is little evidence of the committee currently being active on informal sector matters. Hence, even though some groups of traders were able to use the established name and personal contacts of the leader of the umbrella association VIBINDO 
to access official structures, this has been in an ad-hoc manner with no institutional guarantee for consultation or representation.

The case of micro-traders further illustrates how access to trading space whether illegal, legal, or simply tolerated - is sometimes the context on which institutional power depends. Hence, a low-level form of institutional power is available to associations of members who trade in a local government-sanctioned place. Such groups often have a form of representation in a market council, and through this, they have some access to negotiate with local authorities on behalf of their members.

In the case of informal transport workers in Kenya, we see another form of institutional influence in that the legal framework in place for matatu transport is very influential in regulating the relationship between the transport workers and the owners of the vehicles although not always in ways intended. Hence, while the workers require SACCOs' clearance in order to get the mandatory road service license and badges to operate in the sector, the SACCOS mostly favour the interests of vehicle owners in terms of securing the smooth operation of their vehicles rather than guaranteeing that workers' rights are respected or their opinions voiced.

For informal construction workers, the relationship between informal worker associations and employers (which are sometimes public entities) is at times institutionalized in that some of the better organized and resourced associations are able to bid for tenders and win formal contracts. This was visible in the case of FundiTech service cooperative in Kenya and Sinza Kijiweni Construction in Tanzania which were collaborating with local authorities for contracts. Labour Link in Kenya, a loose network of construction workers, had also nurtured relations with private firms and was able to get contracts.

In the transport sector in both countries and in the micro-trade sector in Tanzania, we saw informal workers tapping into established tripartite structures via affiliation with newly formed or established trade unions. In Kenya, the established transport sector union (TAWU) began to recruit amongst informal workers only in 2018 , but, according to the secretary general, they had recruited around 1,000 matatu workers from five SACCOs and negotiated a collective bargaining agreement with one of them. They have been in the process of changing the constitution to better accommodate informal workers; yet, it remains unclear what rights were to be awarded to informal members internally in the union ( $\mathrm{Ri}$ isgaard, 2021). In addition, Kenya Matatu Workers Union (MWU), registered in 2013, organizes around 1,000 informal matatu workers. The key service they provide to members is to represent them when problems occur - for example, delayed payment from the employer or issues involving the police, but unlike the more established unions, MWU still does not have the capacity to represent members in the court system (ibid.). Further, the Public Transport Operators Union (PUTON) in Kenya represents workers in transport-oriented businesses, including the digital platform workers. In general, however, informal transport workers were found either not interested in joining the available unions or fearing victimization by employers, including SACCOs in Kenya. 
In Tanzania, three different unions are of relevance to daladala and bodaboda riders. COTWU-T is the established trade union which - similarly to Kenya - has been weakened by breakaway unions. At the time of the interviews, COTWU-T had active engagement with three informal worker associations of which one consisted of clerks at a bus terminal while another one consisted of bodaboda riders. The last was a group of women fast food providers working at a bus terminal.

The informal associations are incorporated as branches, and the paying informal members are awarded the same rights within the union as formal members. COTWU-T also used to organize a larger group of daladala workers, but they have since broken out and registered their own union TAROTWU. Another new union is Tanzania Association of Drivers Union (TADU) that represents bodaboda workers and those that operate smaller vehicles like bajaji. The latter two unions, in cooperation with a union for long distance bus drivers, are attempting to form a federation of informal transportation workers' unions with the aim of representing informal transport workers as a distinct voice in tripartite forums. However, that kind of representation is currently limited to affiliates to the established federation TUCTA.

In Tanzania, some informal associations - primarily working in markets have during the last decade or so been incorporated into the established trade union TUICO as affiliate unions. A newer initiative from TUICO, originating in an externally funded programme with StreetNet International, has established a bargaining committee with two members from each of the market-based branches with the aim of providing a bridge between the municipal authorities and traders. The increasing (although still very limited) incorporation of informal trader associations into trade unions has to some degree opened up an institutionalized space for representation and voice for informal traders, albeit as part of the trade union movement in the established institutional model and in addition through this innovative bargaining committee, although further research is needed to assess its current functionality.

In summary, very few informal workers are yet organized into trade unions. Most successful so far has been the transport sector where both new and established unions are involved, however in a very fragmented and competitive manner. In general, the recent opening towards informal workers poses a very difficult and politicized challenge for the established unions, as discussed in more detail by Riisgaard (2021). Notwithstanding the difficulties, inclusion provides an interesting potential for increasing institutional power by tapping into established institutional setups. In the conclusion, we discuss this in relation to different representational models and in comparison with the informal workers' grassroots associations.

\section{Structural power}

In line with Silver (2003), structural power can be divided into workplace bargaining power (the power that can be utilized from the strategic location of a 


\section{2}

certain group of workers in a key sector) and marketplace power (relating to the tightness of the labour market). Activities in the informal economy are most often characterized by low entry barriers, and since the availability of labour is vast, informal workers will, in general, command weak marketplace power. Nonetheless, strategic disruption abilities exist, although they differ greatly by sector. This is of key importance for informal transport workers who, if coordinated, can bring the city circulation to a chaotic halt. Even though transport worker associations are fragmented in both countries, their existence and the fact that they could create considerable disturbance if provoked is acknowledged by public officials.

The potential for workers to disrupt transport operations and hence the circulation of people and goods in the cities is real and has been witnessed in both countries, for instance, to demand for improvement of road infrastructure or protesting police harassment and crackdowns. Another example is provided by the motorcyclists whose approach is often to block streets en masse, to demand for workers' rights to urban spaces. For informal construction workers, the disruption potential is limited to specific construction sites. In Kenya, a few cases were reported where associations had used disruptive power to storm work sites to be heard as they demanded their rights, in particular, regarding payment owed; yet, these were isolated cases with the ability to disrupt limited to particular building sites. For informal micro-traders, disruptive power is of less potential save from the latent ability to physically block certain areas via demonstrations.

Regime-disruptive power - the ability "to cause disruption to, and on that basis extract concessions from, political elites interested in regime-survival" (Marslev, 2019 , p. 18) - is a potentially potent source of power for informal economy workers as an overall group due to their vast numbers and strategic importance, especially as 'vote-banks' during election times. In particular, the fast-growing group of bodaboda riders has become increasingly important in political campaigns, for example, in Tanzania, where the opposition leader would pose with bodaboda riders in the run up to the local elections in 2019. Bodaboda riders are also used strategically in the protests of other groups as, in Kenya, it is now common practice to hire bodabodas to boost street protests regardless of the topic of protest.

However, the common occurrence of splinter-groups and the lack of any consolidated sector wide organizations amongst bodaboda riders and transport workers more generally in both Kenya and Tanzania means that, so far, their potential for exercising regime disruptive power is limited. This notwithstanding, in Kenya, there is a budding national umbrella organization (BAK) of bodaboda riders, which, if well nurtured by members, could provide a platform for negotiation and engagement with authorities. The matatu sector has also occasionally succeeded in mobilizing regime-disruptive power to gain concessions. A similar potential exists in the micro-trade sector due to the vast number of people working in the sector. Nonetheless, even the largest umbrella associations still organize only a fraction of the actual micro-trader populations and hence also in this sector, regime disruptive power so far remain largely as potential. 


\section{Societal power}

Societal power arises from cooperation with other social groups and society's support for worker demands (coalitional power and discursive power). In the context of informal workers, this relates to coalition making with other informal associations, with formal worker associations, and with broader civil society organizations.

In construction, coalitional power, in general, is absent in Tanzania but evident in Kenya where associations are working with Non-Governmental Organizations (NGOs) and development partners which provide linkages to services and resources. Tanzanian associations are noted to be inward-looking, concentrating on immediate needs without umbrella associations, while, in Kenya, umbrella association exist, although many construction associations and workers are not (yet) members.

Although the micro-trade sector is poorly coordinated, the findings do show potential in greater coordination to enhance associational power as umbrella associations were found to be more robust and able to represent members and facilitate access to services such as loans, training, or health insurance. In addition, a few recent attempts at broader coalitions and cooperation between different types of associations have taken place in Tanzania, perhaps pointing towards a future strengthening of societal power. In addition, support from external organizations such as, for example, foreign NGOs and connections to people in power also figured prominently in some of the cases explored in this book. Hence, in both countries, the two largest and most established umbrella associations (KENASVIT and VIBINDO) had been, and are, receiving support from external organizations such as foreign NGOs and private actors. Finally, favourable statements made by the late president Magufuli in a top-down manner shape public discourses towards a more favourable view on micro-traders which could potentially be harnessed by associations to achieve increased societal power.

Associations in the transport sector, as mentioned, are very fragmented and competitive. Nonetheless, external coordination - like when the International Transport Federation calls for cooperation around campaigns related to the planned implementation of a Bus Rapid Transit system in Kenya - can trigger coalitional power on a case-by-case basis. As mentioned, the nascent affiliation of informal transport associations to established unions is also an example of coalitional power, with potential to spill over into discursive power, like when a group of Bodaboda and COTWU-T marched together on May Day in 2019 in Dar es Salaam with banners that read: "A Boda-boda job is like any other job". The event was reported positively by the media with citizens giving testimony on how much they relied on Bodaboda. This also got the attention of the Dar es Salaam Regional Commissioner and the Mayor of the city, and hence bodaboda representatives were invited to their respective offices for consultation regarding their work.

In summary, as also highlighted in the literature on PRA, we see different power resources reinforcing each other but also observe how most power 


\section{4}

Winnie Mitullab et al.

resources in the informal economy remain underexploited due to fragmentation, lack of resources, and, in general, weak structural bargaining power.

\section{Services provided by associations}

Although associations have different frameworks for offering informal social protection, in general, associations remain the bedrock of informal workers' social protection in both countries. While the associations do not use conventional formal social protection concepts such as social assistance, social security, and health insurance, much of the welfare cushioning they provide for workers falls within these social protection categories. It largely falls on preventive social insurance ranging from one-off responses to specific problems to more specific insurance schemes. Almost all associations support members during sickness and death, with a few others intermittently supporting maternity and unemployment. These kinds of support are not comprehensive and vary across sectors, countries, and associations, and some of the main differences emerging across sectors and types of social protection are discussed below.

The following discussion of the specific services offered by associations uses a typology of social protection elaborated by Devereux and Sabates-Wheeler (2004). They distinguish between four main social protection types: protective, preventative, promotive, and transformative. Protective measures largely overlap with social assistance and, as mentioned, are not covered by our project. Preventive measures include both formal social insurance programmes - such as pensions, health insurance, and maternity leave - and informal insurance. Promotive measures function to enhance or stabilize income, consumption, and capabilities and include access to finance or training, while transformative measures address social equity and exclusion, for example, through collective action and representation. As the latter has been dealt with in detail using the PRA, below, we focus on preventive and promotive measures.

\section{Preventive}

When it comes to leveraging associations for accessing (preventive) formal social protection in the construction sector, both countries do not perform well as indicated by the relatively low share of members that have formal health and pension cover (see Table 10.1). As a result, in both Tanzania and Kenya, construction workers exposed to hazardous working environments have created self-cushioning informal mechanisms, although these schemes only provide partial coverage to workers. In most cases, workers have to pay for themselves since they have neither formal social protection cover nor any collateral and insurance to cushion them from life challenges.

Across the two countries, construction associations ensure that injured colleagues are taken to hospital, with some Tanzania associations supporting colleagues even after being discharged from hospital and while on sick leave. In both countries, employers hardly fully take care of the injured, some make one-off 
payments. Further, in both countries, some associations had dedicated specific funds to welfare, with one Kenyan association noting that, "we are building our own insurance, having emergency fee for accidents occurring on site". Furthermore, in both countries, construction workers complement group contributions with additional one-off contributions depending on the welfare needs of members at a given time. This is done by mobilizing resources among members as an additional cushioning measure to any member with a critical welfare issue such as admission to hospital or death.

In the transport sector, workers are more likely to access formal insurance measures, especially in Kenya due to the SACCOs paying for the workers' NHIF and NSSF coverage. Moreover, for those who are employed by bus companies, the company makes regular contributions to the NHIF to cover the enrolled members. However, as in construction, workers are exposed to occupation health and safety issue and prone to accidents and rely on associations and SACCOs for insurance. The Tanzania associations tend to be stronger in providing informal social insurance with some having different levels, for example, support for death in the immediate family and upon death, survivor's cushioning which is similar to formal survivors' pension, although the social insurance may not be as comprehensive and long term. In cases where associations are not strong, members spontaneously help colleagues who require assistance through informal fund-raising and leveraging of funds. In the Kenyan transport sector, there is more of a mix of formal and informal insurance leveraged through associations. In the latter case, workers' groups sometimes form sub-groups for savings and credit. It seems that many transport workers are reluctant to join formal schemes which partly explain why there are sub-groups to provide informal insurance when SACCOs are encouraging workers to join the formal schemes.

Some associations, in particular, in the trade sector, provide for social insurance in their constitutions, specifying the structure of support, rules, and social funds. This structured approach was more latent in Kenya compared to Tanzania, with one association having an emergency fund to which members contribute KES 50 (USD 0.05) daily. In such schemes in both countries across sectors, a member is the point of reference, but other family members, in particular, spouse and children, are largely covered. Other associations extend support to parents and relatives who are part of a members' household. However, support is provided on a reduced level for non-members and mainly includes sickness, in particular, admission to hospital, and death. Other areas which are supported but often on an ad-hoc basis or through loans are school fees, unemployment, funerals, and weddings. As the trade sector is dominated by women, women are, in some cases, also supported during maternity. In Kenya, some associations exempt nursing mothers from attending association meetings and assist women to manage their businesses while on maternity to ensure income for paying association contributions and for survival, while others contribute a given amount to take care of the expenses of nursing mothers. In Tanzania, some associations support women when hospitalized during delivery. Contrary 
to the Kenya situation, some groups in Tanzania give three months' maternity leave from group responsibilities and subscription fees.

\section{Promotive}

Associations in both countries are active in various promotive roles, in particular, supporting members to save and access credit as well as training in sector skills. In the construction sector across both countries, the promotive role of associations is very vibrant in terms of providing loans. These benefits are almost equal in both countries with very marginal differences. For example, in Tanzania and Kenya, 20 and 18 percent of members had received loans, respectively. This notwithstanding, the associations in Tanzania which were generally young, were wishing for expanded access to micro-credit, which implies that they have not accumulated enough savings through their associations.

Training through construction associations was more active in Kenya than Tanzania, with associations in Kenya partnering with government agencies and other actors in training, which was offered for free. Furthermore, the Kenya associations were working closely with polytechnics, partnering with them in training graduates in construction skills. These aspects were not manifest in Tanzania although associations had plans to take members for formal training. In isolated cases, some associations in both countries were also supporting members to purchase assets, including land, through loans.

Compared to Kenyan workers, a significant number of transport workers in Tanzania rely on associations for access to loans. In Tanzania, SACCOs are primary sources of savings and loans, while for Kenya, there are various types of associations that includes transportation SACCOs mandated by law as well as other SACCOs. In Kenya, associations promote investments through savings, share-holding, or making contributions to purchase SACCO or company vehicles, individual, and association motor vehicles. In Tanzania, associations have encouraged companies to establish lease and buy agreements with members, a few have obtained loans to purchase buses, and for buying motorcycles through loans, while others have approached banks on behalf of their members for loans.

In both countries, associations also facilitate training of members, although Kenya is more vibrant with formal training of members. In Kenya, formal training covers financial literacy, road safety, investment, and exchange visits, while, in Tanzania, informal on-job training was dominant, mainly for motorcyclists, who learn through riding other members' motorcycles.

The trade sector is equally active in facilitating members to access loans from associations and private financial institutions. Savings and loans compliment income and cover life contingencies of association members. In both countries, loans are largely from the pooled monthly membership contributions which attract lower rates of interest compared to other financial institutions. Such loans have flexible payment plans, although not infrequently, funds available are not adequate to meet members' demands. In both Tanzania and Kenya, training facilitated by associations focusing on business skills and entrepreneurship was 
provided by some of the better organized associations. In Tanzania, in some cases, such training resulted in income generating activities and bulk buying for advancement of association members.

\section{Key findings}

As discussed in this edited volume, informal workers across different sectors in Kenya and Tanzania share many attributes, including the fact that a significant percentage of workers operate in a fragile environment without adequate social protection. This chapter's comparative analysis of the construction, transport, and trade sectors across the two countries shows many synergies in respect to the working environment and the importance of associations, especially in respect to cushioning workers on welfare issues. Major differences between the sectors relate to the nature of organization, in which the trade and transport sectors manifest a higher level of organization compared to construction sector. The two former sectors have well-established grassroots and umbrella associations, and there are signs of them beginning to join unions for better representation and voice. Apart from these overarching findings, the sector and country comparisons bring out several other key findings as highlighted below.

A higher percentage of workers are enrolled in associations in Kenya than in Tanzania, and Kenya associations tend to overall be more resourceful than Tanzanian associations. In Kenya, workers have higher level of institutional power, especially in the transport and trade sectors, while Tanzania has made some adhoc interventions in both sectors which are not institutionalized.

In respect to services, Tanzanian traders are more engaged in social cushioningtype associations, while Kenya traders primarily belong to loan-related associations. In both countries, traders' associations, especially those located in markets, negotiate with local government authorities for trading spaces and infrastructure with different levels of success. In Tanzania, there is nascent trade union involvement with micro-traders, an aspect which has potential for improving the situation of traders. Larger umbrella associations in both countries were found to offer higher levels of support to members, including access to training, infrastructure, and representation. In a way, these umbrella associations play a role similar to unions, and it might be useful for future research to examine this relationship. Although the majority of workers are not in umbrella associations and unions, there are signs, especially in Tanzania, of unions attempting to design appropriate models to accommodate the unique characteristics of informal work.

In the transport sector, there is a remarkable difference between Tanzania and Kenya associations, although, in both countries, workers operate under loose agreement with vehicle owners. Kenya associations operate within a quasi-legal environment - an aspect which should be empowering but it is not, as SACCOs are skewed towards vehicle owners, with minimal benefit to workers. However, well-functioning associations, SACCOS, and companies invest in workers' capacitybuilding, organize trainings on road safety and financial literacy, and also invest in social protection. In comparison to Kenya, Tanzanian transport workers 
operate more informally, and the sector is dominated by fragmentation and disintegration of associations, although some Regional Commissioners encourage route associations to form larger umbrella associations for ease of coordination and governance. While this seems to be an advantage to government, associations can exploit such formations to their own advantage in advancing their transformative power.

Construction workers lag behind in organizing in both countries. Tanzania has young associations compared to Kenya, but associational performance levels in both countries are almost similar, except for the ability of Kenya construction associations to use promotive power. They leverage partnerships both at the local and international level to advance the skills of workers.

There are signs of associations exerting different forms of power across the two countries, with associational power being the most vibrant. Through associational power, associations support workers to access preventive, promotive, and minimal transformative services. Structural power is limited in all sectors, although both transport and construction sectors have the potential to disrupt cities and sites of operation to demand rights. In both countries, this power is limited among traders and only used occasionally by construction workers in specific work sites. Societal and institutional power is also present, but more visible in Kenya. In respect to societal power, construction workers in Tanzania are inward-looking, limitedly leveraging support from NGOs, people in power, and private actors. Although the transport sector in both countries is poorly coordinated, on-going external support and coordination has the potential of triggering coalition power for driving the sector needs. On-going external support also features prominently in the trade sector amongst the larger umbrella associations.

In sum, whether in terms of power resources, worker challenges, or associational benefits, most of the differentiation manifests itself on a sectoral basis, in turn, underscoring the importance of adopting a sector-specific lens when analyzing the realities of informal workers.

\section{References}

Devereux, S. \& Sabates-Wheeler, R. (2004) Transformative social protection. IDS Working Paper 232. Brighton, Institute of Development Studies.

ILO (1972) Employment, incomes and equity: A strategy of increasing productive employment in Kenya. Geneva, International Labour Office.

ILO (2019) World employment and social outlook: Trends 2019. Geneva, International Labour Office.

Jacob, T. \& Pedersen, R.H. (2018) Social protection in an electorally competitive environment (2): The politics of health insurance in Tanzania: ESID Working Paper 110. Manchester, The Effective States and Inclusive Development (ESID) Research Centre. KNBS (2019) Economic survey 2019. Nairobi, Kenya National Bureau of Statistics.

Marslev, K. (2019) The political economy of social upgrading. A class-relational analysis of social and economic trajectories of the garment industries of Cambodia and Vietnam. $\mathrm{PhD}$ thesis. Roskilde University. 
Riisgaard, L. (2021) Organizing the informal economy as part of the trade union movement in Kenya and Tanzania. CAE Working Paper No. 1, 2021. Roskilde, Roskilde Universitet.

ROK (2010) Constitution of Kenya. Republic of Kenya. Nairobi, Government Printer.

ROK (2019a) Basic education statistical booklet. Nairobi, Ministry of Education, Republic of Kenya.

ROK (2019b) Kenya population census. Nairobi, Kenya National Bureau of Statistics (KNBS).

Schmalz, S., Ludwig, C. \& Webster, E. (2018) The power resources approach: Developments and challenges. Global Labour Journal. 9 (2), 113-134.

Silver, B.J. (2003) Forces of labor: Workers' movements and globalization since 1870. Cambridge, Cambridge University Press.

Spooner, D. \& Manga, E. (2019) Nairobi bus rapid transit: Labour impact assessment research report. Manchester, Global Labour Institute.

UN (2019) World population prospects 2019. Department of Economics and Social Affairs, United Nations (UN-DESA). New York, UN-DESA.

URT (2019) Pre-primary, primary, secondary, adult and non-formal education statistics. Dodoma, Tanzania, President's Office, Regional Administration and Local Government. 